\title{
Rice Husk Coated Chitosan Biocomposite as an Adsorbent for Cadmium Removal from Aqueous
}

\author{
Alyza A. Azmi ${ }^{1}$ (D), Nur Farah Nabilah Roslan ${ }^{2}$, M.H.C. Harun ${ }^{2}$ (D), Azzam A. M. Abuhabib ${ }^{3}$ (D), Sofiah \\ Hamzah $2, *$ (D) \\ Faculty of Science and Marine Environment, Universiti Malaysia Terengganu, 21030 Kuala Nerus, Terengganu, Malaysia \\ 2 Faculty of Ocean Engineering and Informatics, Universiti Malaysia Terengganu, 21030 Kuala Nerus, Terengganu, \\ Malaysia \\ 4 Disaster \& Crisis Management Master Programme, Islamic University of Gaza, Palestine \\ * Correspondence: sofiah@umt.edu.my;
}

Scopus Author ID 55023192300

Received: 29.05.2020; Revised: 26.06.2020; Accepted: 28.06.2020; Published: 3.07.2020

\begin{abstract}
The main goal of this research was to evaluate the effectiveness of rice husk coated with chitosan as a green adsorbent for the removal of cadmium (II) in aqueous solution. The properties of prepared rice husk-chitosan (Chi-RH) were characterized using SEM, FTIR, and XRD analysis. The main parameters that influence cadmium sorption on the Chi-RH biocomposites were evaluated at different stirring and contact time, adsorbent dosage, and $\mathrm{pH}$ values. The results indicated that the best stirring time and contact time was 360 mins and 60 mins, respectively. The optimum adsorbent dosage was $1.0 \mathrm{~g} / \mathrm{L}$, with the highest percentage removal of $99 \%$, and the optimum $\mathrm{pH}$ was 9 . This study concluded that the Chi-RH biocomposites have the high ability as a green adsorbent for cadmium removal in aqueous solution and simultaneously reducing the environmental impact.
\end{abstract}

Keywords: rice husk; chitosan; green adsorbent; cadmium removal.

(C) 2020 by the authors. This article is an open-access article distributed under the terms and conditions of the Creative Commons Attribution (CC BY) license (https://creativecommons.org/licenses/by/4.0/).

\section{Introduction}

Cadmium is one of the heavy metals, which is highly toxic, nondegradable, persistent, and has adverse impacts on living organisms. Cadmium exposure is a high-risk factor associated with nephropathy, angiocardiopathy, and bone lesions [1-3]. It can bioaccumulate in kinds of seafood, and long-term exposure to cadmium may cause high blood pressure, liver disease, and nerve or brain damage [4-6]. The main anthropogenic pathway through which cadmium enters the environment is via wastes from industrial processes such as alloy manufacturing, pigments, electroplating, plastic, cadmium-nickel batteries, smelting, fertilizers, pesticides, mining, pigments and dyes, textile operations and refining [7-9]. Therefore, to secure human health, it is imperative to decontaminate the cadmium contaminated water efficiently before being discharged.

Over the years, many physical and chemical techniques, including ion exchange, filtration, sedimentation, and electrochemical treatment, have been done for heavy metal remediation [10-13]. However, these methods suffer from such limitations as a high operating cost and hazardous secondary pollutant formation that have restrained their widespread applications. In recent years, the adsorption of heavy metals from aqueous environments using green materials prepared from various biogenic sources have been studied extensively [14-16, 
17]. The approach offers several advantages, including simple material preparation, economical, and effective.

Rice husk is one of the agriculture waste products that has potentially been used as a natural adsorbent in pollutant removal as it is chemically stable in an aquatic environment. [1820]. The major components of rice husk are cellulose, hemicellulose, and lignin that facilitate the adsorption of heavy metal. In this study, the adsorption capacity of the rice husk towards $\mathrm{Cd}^{2+}$ ions was enhanced by modification with chitosan. The modification has altered the physical morphology and chemical properties of the biocomposites for the $\mathrm{Cd}^{2+}$ removal performance. The combination of rice husk and chitosan, which denoted as Chi-RH biocomposites, were characterized and adsorption study was carried out at different parameters such as stirring and contact time, adsorbent dosage and $\mathrm{pH}$ of the solution.

\section{Materials and Methods}

\subsection{Preparation of rice husk adsorbent.}

The rice husk sample was obtained from a local company located in Terengganu. The rice husk was washed several times using deionized water to remove any impurities, and heated in an oven at $180^{\circ} \mathrm{C}$ for 6 hours. The dried rice husk then ground and sieved within the size range of $350-250 \mu \mathrm{m}$. The powder was allowed to blend with concentrated $\mathrm{H}_{2} \mathrm{SO}_{4}$ at a temperature range of $170-180{ }^{\circ} \mathrm{C}$ for $20 \mathrm{~min}$, cooled, and filtered using Buchner funnel. The material was then washed again with deionized water for several times to remove any acid residue.

\subsection{Preparation of chitosan-loaded rice husk (Chi-RH).}

Chitosan powder with deacetylation percentage $>90 \%$ was purchased from a standard local supplier. A $2.5 \mathrm{wt} \%$ chitosan solution was prepared by dissolving $5 \mathrm{~g}$ of chitosan powder in $5 \mathrm{~mL}$ of $2.5 \%(\mathrm{v} / \mathrm{v})$ acetic acid solution with continuous stirring at $600 \mathrm{rpm}$ overnight to obtain a homogenous solution. The prepared rice husk materials were added to the chitosan solution under heating for the time range between 2-6 hours, and the final product, denoted as Chi-RH biocomposite, was formed. The material was washed with deionized water and dried in an oven overnight at $50{ }^{\circ} \mathrm{C}$. The obtained product of Chi-RH was preserved at room temperature for further analysis and adsorption study.

\subsection{Characterization of Chi-RH biocomposites.}

The spectroscopy and surface morphology of the Chi-RH were observed using Fourier Transform Infrared (FTIR), and Scanning Electron Microscope (SEM), respectively. The Xray diffraction patterns of Chi-RH biocomposite were studied using X-ray Diffractometer (Rigaku II) using $\mathrm{Cu} \mathrm{K} \alpha$ as an $\mathrm{X}$-ray radiation source.

\subsection{Batch adsorption for Cd(II) removal.}

The adsorption of $\mathrm{Cd}^{2+}$ ions in aqueous solution was carried out based on batch adsorption mode. A $100 \mathrm{~mL}$ of the prepared $\mathrm{Cd}^{2+}$ solution at different concentrations was mixed and shaken with $0.1 \mathrm{~g}$ of the Chi-RH materials at ambient temperature. The effect of stirring time for chitosan in the rice husk was studied at 2 hours (Chi-RH2), 3 hours (Chi-RH3), 4 hours (Chi-RH4), 5 hours (Chi-RH5), and 6 hours (Chi-RH6). The biocomposite-Cd ${ }^{2+}$ ions 
contact time was studied in the range time between 30 to 150 minutes. Other parameters such as adsorbent dosage, the concentration of $\mathrm{Cd}^{2+}$, agitation speed, and $\mathrm{pH}$ were kept constant throughout this batch.

The adsorbent dosage effect towards $\mathrm{Cd}^{2+}$ removal was studied in the range of 0.2 to 1.0 g/L, denoted as Chi-RH0.2, Chi-RH0.4, Chi-RH0.6, Chi-RH0.8, and Chi-RH1.0. Other parameters such as chitosan-rice husk stirring time, the concentration of $\mathrm{Cd}^{2+}$, agitation speed, and $\mathrm{pH}$ were kept constant throughout this batch. The samples were filtered and analyzed using Atomic Absorption Spectrophotometer (AAS), and the removal of $\mathrm{Cd} 2+$ by $\mathrm{Chi}-\mathrm{RH}$ biocomposites was evaluated by percentage removal $(\%)$ using the following equation:

$$
\% \text { removal }=\frac{\left(C_{V}-C_{O}\right) 100}{C_{O}}
$$

Where, $\mathrm{CV}_{\mathrm{v}}$ is the volume of the $\mathrm{Cd}^{2+}$ solution $(\mathrm{L})$, and $\mathrm{Co}_{\mathrm{O}}$ is the initial concentrations of the metal ion $\left(\mathrm{mg} \mathrm{L}^{-1}\right)$.

\section{Results and Discussion}

\subsection{Characterization of Chi-RH biocomposites.}

Figure 1 shows SEM images of the morphology characteristic of the rice husk before (Figure 1(a)) and after chitosan loading (Figure 1(b)). The rice husk showed a formation of polydisperse particles with various sizes and combinations of smooth structure and globule structure. It also showed regular criss-cross framework construction and needle-like structure that gives an advantage to the rice husk as a good adsorbent. After modification with chitosan, the formation of porous and fibril structure, less globule with the lamellar surface organization were observed. Furthermore, some dark contrast of straps and shrinkage on the surface (inset b) represent opening pores, which indicates the potential of the prepared material for adsorption of heavy metal. This morphology nature finding is consistent with the study by Gokila et al. (2017). It shows higher heavy metal removal compared to the native one [21].
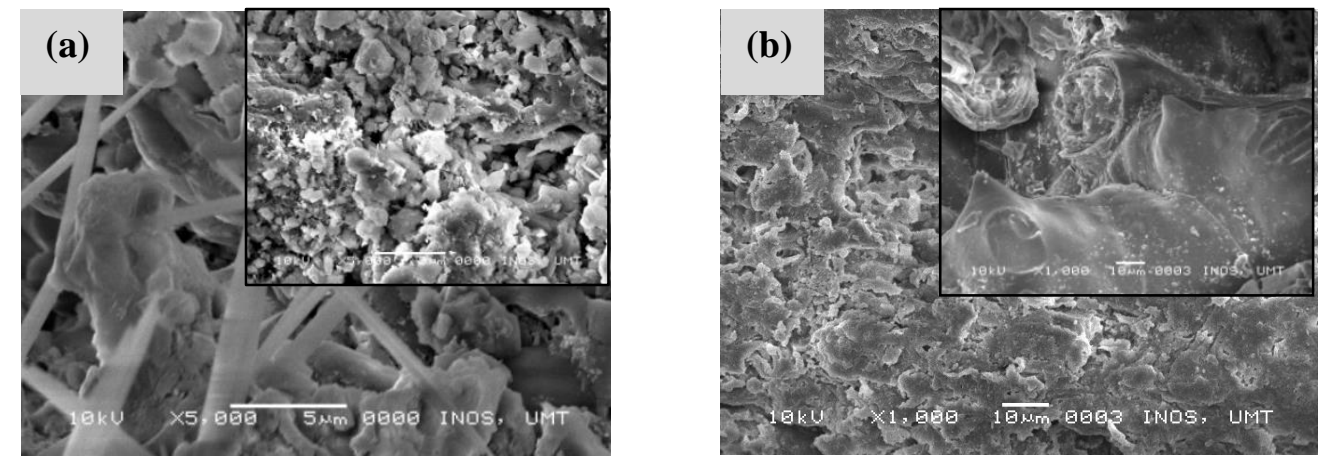

Figure 1. SEM micrograph of (a) bare rice husk, and (b) after chitosan loading (Chi-RH).

Figure 2 shows the FTIR spectra of chitosan and Chi-RH biocomposite at a wavelength range of 4000 to $650 \mathrm{~cm}^{-1}$. A strong absorption band at $3430 \mathrm{~cm}^{-1}$ in both spectra were attributed to the stretching vibration of $\mathrm{O}-\mathrm{H}$ and $\mathrm{N}-\mathrm{H}$ groups, as well as intramolecular hydrogen bonds [22]. The absorption band at around $2926 \mathrm{~cm}^{-1}$ and a shoulder near $2852 \mathrm{~cm}^{-1}$ correspond to the symmetric and asymmetric stretching of $-\mathrm{CH}$ and $-\mathrm{CH}_{2}$ on aliphatic-saturated, which a typical characteristic band for polysaccharide compounds [21]. This may give information on the presence of cellulose or hemicellulose components in the prepared Chi-RH biocomposites. 
The peaks at $1645 \mathrm{~cm}^{-1}$ and $1380 \mathrm{~cm}^{-1}$ in chitosan powder shows the presence of $\mathrm{C}=\mathrm{O}$ and $\mathrm{C}-\mathrm{N}$ stretching from the residual of $\mathrm{N}$-acetyl groups, which indicates the parent chitin [23]. A broader peak was observed around the same region for the Chi-RH confirms the presence of organic ester linkage for hemicelluloses and lignin. The bands obtained in the region of 1400$1300 \mathrm{~cm}-1$ for the Chi-RH biocomposites indicate the stretching of $\mathrm{C}=\mathrm{C}$ groups [21, 24], represents the lignin composition, while a shoulder peak in the same region for chitosan powder indicates the bending and deformation of $=\mathrm{CH}$ and $-\mathrm{CH}_{2}$ groups. A sharp absorption band at $1080 \mathrm{~cm}^{-1}$ in chitosan power was attributed to C-O stretching [25, 26]. The peak appears broader in the Chi-RH due to the overlapping between $\mathrm{C}-\mathrm{O}$ and $\mathrm{O}-\mathrm{H}$ stretching from polysaccharides cellulose [21]. The reduction of the peak intensity of several adsorption bands indicates the covalent and non-covalent interaction took place between chitosan and rice husk, and the biocomposites were successfully prepared.

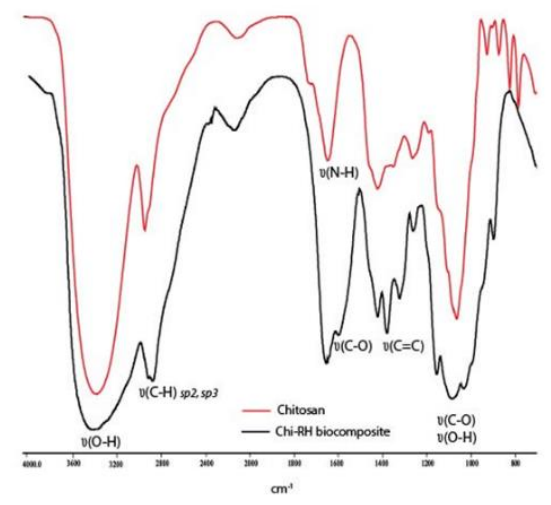

Figure 2. FTIR spectrum of the Chi-RH biocomposites (black line) and Chitosan powder (red line).

Figure 3 shows the XRD pattern of chitosan powder and the Chi-RH biocomposites. The amorphous nature of the chitosan was confirmed by a broad peak at $2 \theta$ scale of $20^{\circ}$ [ 25 , 27]. The appearance of the peak was observed again after the formation of Chi-RH biocomposites, indicates the chitosan was successfully coated on the surface of rice husk particles. A shoulder peak in the region of $38^{\circ}$ corresponded to the peak diffraction of cellulose [28].This finding was consistent with the study conducted by Purwaningsih et al. (2019).

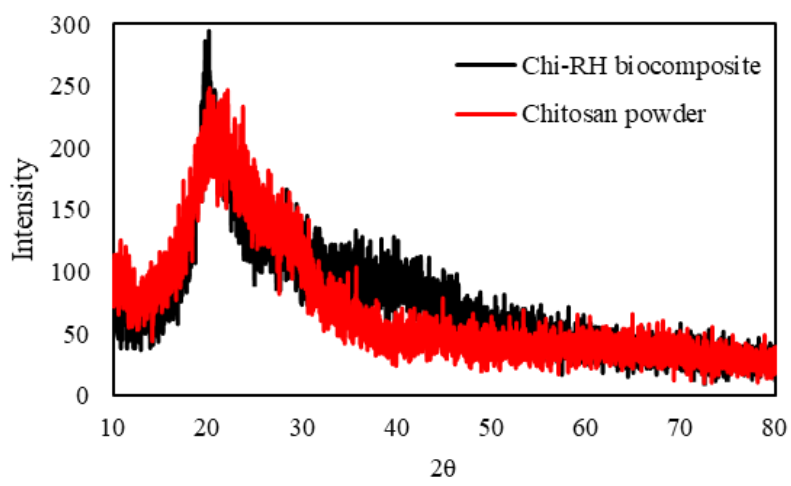

Figure 3. X-ray diffraction pattern of the chitosan powder (red) and the Chi-RH biocomposite (black).

\subsection{Adsorption of $\mathrm{Cd}^{2+}$ ions on the Chi-RH biocomposites.}

\subsubsection{Stirring time and contact time.}

Figure 4 shows the effect of stirring time and contact time on the adsorption of $\mathrm{Cd}^{2+}$ with other parameters were kept constant. The stirring time chose 2 to 6 hours, which 
correspond to the Chi-RH2 to Chi-RH6, respectively. The result showed that the optimum stirring time of chitosan and rice husk was 6 hours, with the maximum removal rate of $96 \%$ at 60 minutes of contact time. It is consistent with the fact that a high composition of cellulose and hemicellulose offers hydroxyl functional groups as active adsorption sites, while the presence of amino groups on the surface of chitosan enhances the ability of the Chi-RH biocomposites to bind with the $\mathrm{Cd}^{2+}$ ions through electrostatic attractions [29]. The combination of both functional groups contributed from rice husk, and chitosan offers a large number of sorption sites towards the removal of $\mathrm{Cd}^{2+}$ ions, thus decrease the reaction contact time to achieve equilibrium. The adsorption was saturated at 150 minutes, indicates the pore spaces were occupied, and the interaction was dominated by electrostatic repulsion [30]. Therefore, the binding capacity was weakened, and the adsorption ability was decreased.

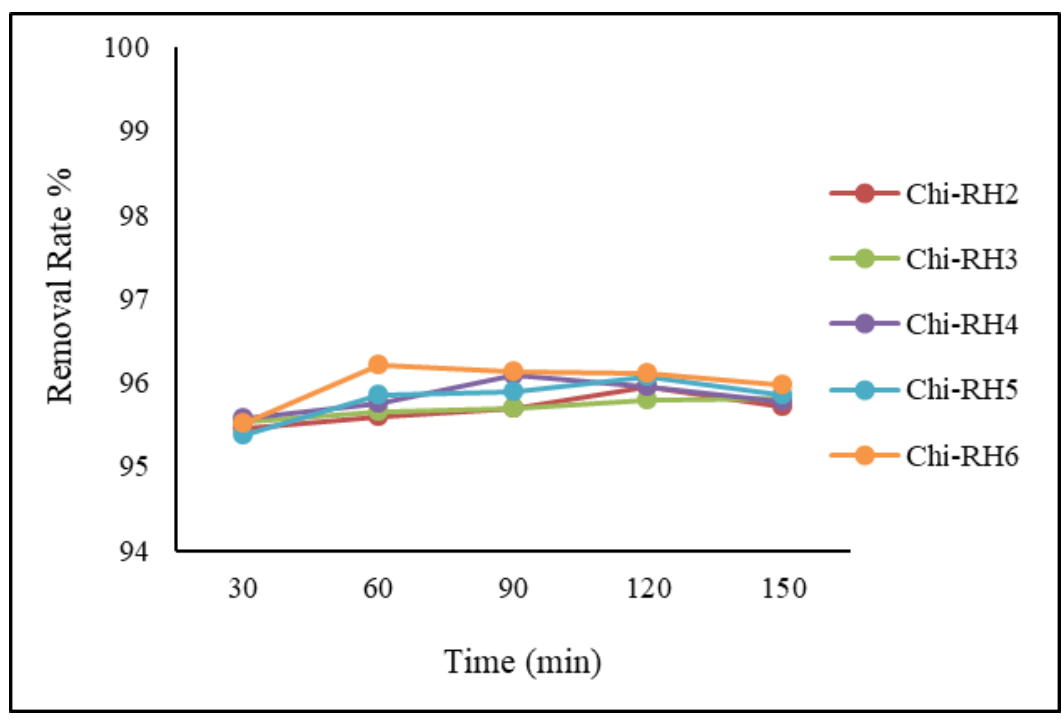

Figure 4. The effect of stirring and contact time on Cd (II) removal.

\subsubsection{Effect of the adsorbent dosage and $\mathrm{pH}$ of the solution.}

The effect of the adsorbent dosage on the removal effectiveness was studied by varying the Chi-RH biocomposite from 0.2 to $1.0 \mathrm{mg} \mathrm{L}^{-1}$ for 150 minutes. The other parameters, including temperature, agitation speed, and concentration of $\mathrm{Cd}^{2+}$ ions $\left(30 \mathrm{mg} \mathrm{L}^{-1}\right)$ were kept constant throughout the reaction. It is shown in figure 5(a) that the highest percentage removal of $\mathrm{Cd}^{2+}$ ions from the aqueous solution was observed at $1.0 \mathrm{mg} \mathrm{L}^{-1}$, approximately $99.4 \%$ at 150 minutes. The dosage of adsorbents determines the total area of the materials available for $\mathrm{Cd}^{2+}$ ions biosorption. Therefore, as the dosage of the Chi-RH is proportional to the specific area of the Chi-RH, the increasing of dosage will contribute to the availability of the binding sites and enhance the adsorption reaction.

The surface properties of the adsorbent, including protonation of the functional groups and the degree of ionization and speciation of the adsorbate, is depending on the $\mathrm{pH}$ values [31]. Figure 5(b) illustrates the $\mathrm{pH}$-dependency of $\mathrm{Cd}^{2+}$ ions removal with adsorption increase with increasing of $\mathrm{pH}$ from 3 to 9 . Cellulose was positively charged at a lower $\mathrm{pH}$ value. Thus it was not suitable for the heavy metal cation adsorption. Furthermore, the amine groups on the surface of chitosan were protonated and preventing the formation of a complex with the $\mathrm{Cd}^{2+}$ ions. This is consistent with the observation at $\mathrm{pH}$ lower than 5 , with percentage removal in the range of $95 \%$ to $96 \%$. Meanwhile, at extreme basic conditions, the solubility of the $\mathrm{Cd}^{2+}$ ions was decreased and precipitated out from the solution, with the main existing compounds were $\mathrm{Cd}\left(\mathrm{OH}_{2}\right)$ and $\mathrm{Cd}(\mathrm{OH})^{-}$. It was observed that the highest adsorption capacity has occurred 
at $\mathrm{pH} 9$, with the percentage removal of $98 \%$. The same pattern was observed by Babakhani and Sartaj (2020).

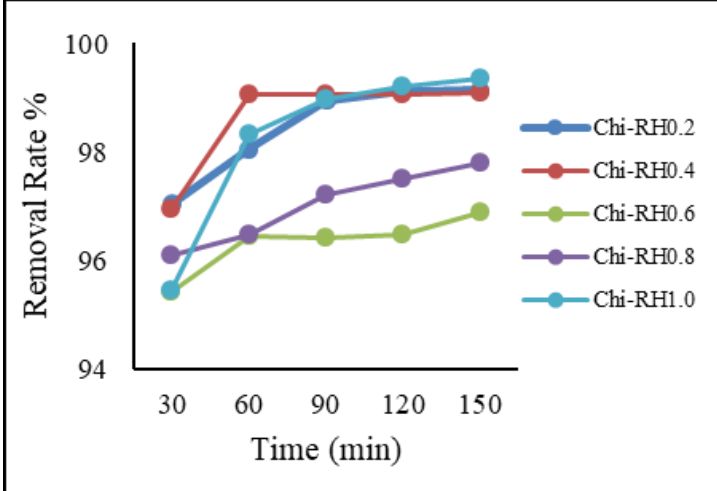

(a)

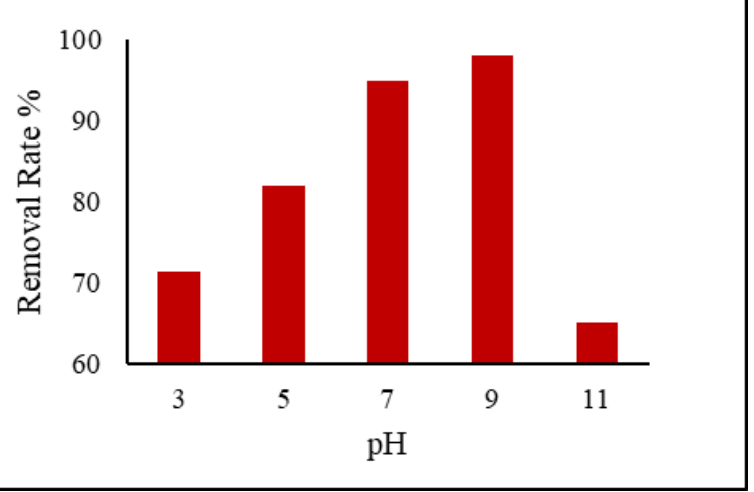

(b)

Figure 5. (a) The effect of adsorbent dosage and (b) $\mathrm{pH}$ of the aqueous solution on the removal of the $\mathrm{Cd}^{2+}$ ions.

\section{Conclusions}

Presently, the Chi-RH biocomposites have demonstrated as an excellent biosorbent for the removal of cadmium heavy metal cations from aqueous solutions. Lignins, cellulose, and hemicellulose components from the rice husk had been recognized to facilitate the adsorption process, while modification with chitosan was enhancing the adsorption ability by offering space and adsorption sites for the $\mathrm{Cd}^{2+}$ ions chelation interactions. The morphology of the prepared Chi-RH biocomposites were successfully characterized using SEM, and the presence of functional groups was confirmed using FTIR spectroscopy. XRD analysis confirmed the amorphous nature of the biocomposites, which serve as excellent candidates for the heavy metal adsorptions. The study also concluded that the effectiveness of the Chi-RH was depending on stirring and contact time, adsorbent dosage as well as $\mathrm{pH}$ of the solutions.

\section{Funding}

This research received no external funding.

\section{Acknowledgments}

The author gratefully acknowledges the Center of Research and Field Service, Universiti Malaysia Terengganu, Malaysia, for providing research facilities.

\section{Conflicts of Interest}

The authors declare no conflict of interest.

\section{References}

1. Authman, M.M.N.; Zaki, M.S.; Abbas, H.H. Use of Fish as Bio-indicator of the Effects of Heavy Metals Pollution. J. Aquac. Res. Dev. 2015, 6, 4-77, https://doi.org/10.4172/2155-9546.1000328.

2. Jan, A.T.; Azam, M.; Siddiqui, K.; Ali, A.; Choi, I.; Haq, Q.M.R. Heavy Metals and Human Health: Mechanistic Insight into Toxicity and Counter Defense System of Antioxidants. Int. J. Mol. Sci. 2015, 16, 29592-29630, https://doi.org/10.3390/ijms161226183

3. Ali, H.; Khan, E. Environmental Chemistry and Ecotoxicology of Hazardous Heavy Metals: Environmental Persistence, Toxicity, and Bioaccumulation. J. Chem. 2019, 6730305, 1-14. https://doi.org/10.1155/2019/6730305. 
4. Jaishankar, M.; Tseten, T.; Anbalagan, N.; Mathew, B.B.; Beeregowda, K.N. Toxicity, mechanism and health effects of some heavy metals. Interdiscip. Toxicol. 2014, 7, 60-72.

5. Bawuro, A.A.; Voegborlo, R.B.; Adimado, A. A. Bioaccumulation of Heavy Metals in Some Tissues of Fish in Lake Geriyo, Adamawa State, Nigeria. J. Environ. Public Health 2018, 1854892, 1-7, https://doi.org/10.1155/2018/1854892.

6. Shi, W.; Zhao, X.; Han, Y.; Che, Z.; Chai, X.; Liu, G. Ocean acidification increases cadmium accumulation in marine bivalves: a potential threat to seafood safety. Sci. Rep. 2016, 6, 2019720205,https://doi.org/10.1038/srep20197.

7. Ayangbenro, A.S.; Babalola, O.O. A New Strategy for Heavy Metal Polluted Environments: A Review of Microbial Biosorbents. Int. J. Environ. Res. Public Health 2017, 14, 94-110, https://doi.org/10.3390/ijerph14010094.

8. Wang, X.S. Cd (II) removal by marine Arthrobacter protophormiae biomass: mechanism characterization and adsorption performance. Desalination Water Treat 2013, 51, 40-42, https://doi.org/10.1080/19443994.2013.781964.

9. Shirsath, D.S.; Patil, B.N.; Shirvastava, V.S. Rapid removal of metals from aqueous solution by magnetic nanoadsorbent: A kinetic study. Int. J. Nano Dimens. 2013, 3, 303-312.

10. Rajasulochana, P.; Preethy, V. Comparison on efficiency of various techniques in treatment of waste and sewage water - A comprehensive review. Resource-Efficient Technologies 2016, 2, 175-184, https://doi.org/10.1016/j.reffit.2016.09.004.

11. Kumar, A.; Balouch, A.; Pathan, A.A.; Mahar, A. M.; Abdullah, Jagirani, M.S.; Mustafai, F.A.; Zubair, M.; Laghari, B.; Panah, P. Remediation techniques applied for aqueous system contaminated by toxic Chromium and Nickel ion. Geology, Ecology and Landscapes 2017, 1, 143-153, https://doi.org/10.1080/24749508.2017.1332860.

12. Qu, J.; Meng, X.; Zhang, Y.; Meng, Q.; Tao, Y.; Hu, Q.; Jiang, J.; You, H., Shoemaker, C.A. A combined system of microwave-functionalized rice husk and poly-aluminium chloride for trace cadmiumcontaminated source water purification: Exploration of removal efficiency and mechanism. J. Hazard. Materials 2019, 379, 120804-120815, https://doi.org/10.1016/j.jhazmat.2019.120804.

13. Foong, C.Y.; Wirzal, M.D.H.; Bustam, M.A. A review on nanofibers membrane with amino-based ionic liquid for heavy metal removal. Journal of Molecular Liquids 2020, 297, 111793-111811, https://doi.org/10.1016/j.molliq.2019.111793.

14. Ali, R.M.; Hamad, H.A.; Hussein, M.M.; Malash, G.F. Potential of using green adsorbent of heavy metal removal from aqueous solutions: Adsorption kinetics, isotherm, thermodynamic, mechanism and economic analysis. Ecol. Eng.2016, 91, 317-332, https://doi.org/10.1016/j.ecoleng.2016.03.015,

15. Martins, A.E.; Pereira, M.S.; Jorgetto, A.O.; Martines, M.A.U.; Silva, R.I.V.; Saeki, M.J.; Castro, G.R. The reactive surface of Castor leaf [Ricinus communis L.] powder as a green adsorbent for the removal of heavy metals from natural river water. Appl. Surf. Sci. 2013, 276, 24-30, https://doi.org/10.1016/j.apsusc.2013.02.096.

16. Sun, S.; Gao, Z.; Li, Z.; Gao, J.; Yuan-Jun, C.; Li, H.; Liu, X.; Wang, Z. Effect of Wood Vinegar on Adsorption and Desorption of Four Kinds of Heavy (loid) Metals Adsorbents. Chinese J. Anal. Chem.2020, 48, e20013-e20020, https://doi.org/10.1016/S1872-2040(19)61217-X.

17. Sharma, S.; Rashmitha, S.; Pandey, L.M. Synthesis and characterization of methyl acrylamide cellulose nanowhiskers for environmental applications. Lett. Appl. NanoBioScience 2020, 9, 880-884, https://doi.org/10.33263/LIANBS91.880884.

18. Shamsollahi, Z.; Partovinia, A. Recent advances on pollutants removal by rice husk as a bio-based adsorbent: A critical review. J. Environ. Manage. 2019, 246, 314-323, https://doi.org/10.1016/j.jenvman.2019.05.145.

19. Ma, J.; Li, T.; Liu, Y.; Cai, T.; Wei, Y.; Dong, W.; Chen, H. Rice husk derived double network hydrogel as efficient adsorbent for $\mathrm{Pb}(\mathrm{II}), \mathrm{Cu}(\mathrm{II})$ and $\mathrm{Cd}(\mathrm{II})$ removal in individual and multicomponent systems. Bioresour. Technol. 2019, 290, 121793- 121800, https://doi.org/10.1016/j.biortech.2019.121793.

20. Hubadillah, S.K.; Othman, M.H.D.; Harun, Z.; Ismail, A.F.; Rahman, M.A.; Jaafar, J. A novel green ceramic hollow fiber membrane (CHFM) derived from rice husk ash as combined adsorbent-separator for efficient heavy metals removal. Ceram. Int. 2017, 43, 4716-4720, https://doi.org/10.1016/j.ceramint.2016.12.122.

21. Gokila, S.; Gomathi, T.; Sudha, P.N.; Anil, S. Removal of the heavy metal ion chromiuim(VI) using Chitosan and Alginate nanocomposites. Int. J. Biol. Macromol. 2017, 104, 1459-1468, https://doi.org/10.1016/j.ijbiomac.2017.05.117.

22. Tajdini, K.; Shakeri, A.; 2, Naijian, F. Nanocomposite hydrogel of chitosan-g-poly acrylamide/ nanoclay: effect of degree of crosslinking on their swelling. Lett. Appl. NanoBioScience 2020, 9, 995-999, https://doi.org/10.33263/LIANBS92.995999.

23. Ahyat, N.M.; Mohamad, F.; Ahmad, A.; Azmi, A.A. Chitin and Chitosan extraction from Portunuspelagicus. Malaysian J. Anal. Sci. 2017, 21, 770-777, https://doi.org/10.17576/mjas-2017-2104-02.

24. Liu, J.; Chen, T.; Yang, Y.; Bai, Z.; Xia, L.; Wang, M.; Lv, X.; Li, L. Removal of heavy metal ions and anionic dyes from aqueous solutions using amide-functionalized cellulose-based adsorbents. Carbohydr. Polym.2020, 230, 115619-115628, https://doi.org/10.1016/j.carbpol.2019.115619. 
25. Shi, Q.; Li, Y.; Wang, L.; Wang, J.; Cao, Y. Preparation of supported chitosan adsorbent with high adsorption capacity for Titan Yellow removal. Int. J. Biol. Macromol. 2020, 152, 449-455, https://doi.org/10.1016/j.ijbiomac.2020.02.265.

26. Ariffin, M.M.; Yatim, N.I.; Hamzah, S. Synthesis and characterization of hydroxyapatite from bulk seashells and its potential usage as lead ions adsorbents. Malaysian J. Anal. Sci. 2017, 21, 571-584, https://doi.org/10.17576/mjas-2017-2103-07.

27. Monier, M.; Bukhari, A.A.H.; Elyased N.H. Designing and characterization of copper (II) ion-imprinted adsorbent based on isatin functionalized chitosan. Int. J. Biol. Macromol. 2020, 155, 795-804, https://doi.org/10.1016/j.ijbiomac.2020.03.215.

28. Meza-Contreras, J.; Manriquez-Gonzalez, R.; Gutiérrez-Ortega, J.A.; Gonzalez-Garcia, Y. XRD and solid state ${ }^{13} \mathrm{C}$-NMR evaluation of the crystallinity enhancement of ${ }^{13} \mathrm{C}$-labeled bacterial cellulose biosynthesized by Komagataeibacterxylinus under different stimuli: A comparative strategy of analyses. Carbohydr. Res .2018, 461, 51-59, https://doi.org/10.1016/j.carres.2018.03.005.

29. Chen, Q.; Zheng, J.; Wen, L.; Yang, C.; Zhang, L. A multi-functional-group modified cellulose for enhanced heavy metal cadmium adsorption: Performance and quantum chemical mechanism. Chemosphere 2019, 224, 509-518, https://doi.org/10.1016/j.chemosphere.2019.02.138.

30. Masih, M.; Anthony, P.; Siddiqui, S.H. Removal of Cu (II) ion from aqueous solutions by Rice Husk CarbonChitosan Composite gel (CCRH) using response surface methodology. Environ. Nanotechnol. Monit. Manag. 2018, 10, 189-198, https://doi.org/10.1016/j.enmm.2018.07.003.

31. Babakhani, A.; Sartaj, M. Removal of Cadmium (II) from aqueous solution using tripolyphosphate crosslinked chitosan. J. Environ. Chem. Eng. 2020, 8, 103842-103854, https://doi.org/10.1016/j.jece.2020.103842. 